\title{
Three-dimensional conformal radiotherapy versus intensity modulated radiotherapy with simultaneous integrated boost in the treatment of locally advanced head and neck carcinoma
}

\author{
M. JIRKOVSKA, T. NOVAK, B. MALINOVA, R. LOHYNSKA* \\ Department of Radiation Oncology University Hospital Motol, 2nd Faculty of Medicine, Charles University Prague, Czech Republic \\ ${ }^{*}$ Correspondence: radka.lohynska@fnmotol.cz
}

Received May 21, 2017 / Accepted July 22, 2017

\begin{abstract}
The treatment of locally advanced head and neck cancer (LAHNC) requires a multimodality approach. Radiotherapy with combination of chemotherapy are demonstrated to be effective, however, the treatment intensification leads to increased toxicity at the same time. The implementation of three-dimensional conformal radiotherapy (3D-CRT) allowed to irradiate the treatment volume more precisely with better surrounding healthy tissue sparing. Intensity modulated radiotherapy (IMRT) facilitated higher conformity in dose shaping to target volume. IMRT with simultaneous integrated boost (IMRTSIB) offered the possibility to deliver individualized dose levels within one fraction and enabled escalation of the dose per fraction and radiotherapy acceleration.

The aim of our study was to compare the technique of 3D-CRT and IMRT-SIB in the treatment of LAHNC and evaluate the treatment outcome and the treatment-related toxicity. 262 patients in 3D-CRT group and 263 patients in IMRT-SIB group underwent the radical treatment for LAHNC between 01/1998 and 12/2016. No statistically significant differences in locoregional control (LCR) and overall survival (OS) were found between the two groups. Acute toxicity and xerostomia were significantly reduced in the patients treated by IMRT-SIB. IMRT-SIB is a safe radiotherapy method where less toxicity was proven without compromising local control and overall survival.
\end{abstract}

Key words: HNC, radiotherapy, 3D-CRT, IMRT-SIB, toxicity

Head and neck cancer (HNC) is the seventh most common cancer with 550000 new cases worldwide every year [1] and 2600 cases in the Czech Republic [2]. The most important risk factors are tobacco and alcohol. In developed countries the decrease of smoking and alcohol exposure corresponds with the decrease of HNC incidence in general. However, other etiology such an infection of Human papilloma viruses leads to an increasing incidence of oropharyngeal carcinoma [3].

For early stages of the disease a single-modality therapy with surgery or radiotherapy are demonstrated highly effective. Locally advanced HNC (LAHNC) requires a multimodality approach. Surgery with adjuvant radiotherapy (radiochemotherapy) or definitive radiochemotherapy have been established as a standard of the treatment strategy. Regardless the multimodality approaches the outcome of LAHNC remains poor. Radiotherapy intensification (4) or the addition of chemotherapy [5] have improved local control and overall survival (OS) but increased acute toxicity at the same time.
Implementation of a technique "three-dimensional conformal radiotherapy" (3D-CRT) based on computed tomography (CT) information permitted an accurate visualization of the tumor and organs at risk (OAR). 3D-CRT took to account the complexity of irradiation volume which includes the primary tumor, pathological lymph nodes and electively irradiated regions; all of them in close proximity to vital structures as the spinal cord or the brainstem. This technique allowed to irradiate treatment volume more precisely with improved surrounding healthy tissue sparing. However, this form of radiotherapy used a few fields technique with a uniform dose and therefore a large volume of normal tissue still received a high radiation dose.

The introduction of intensity modulation radiotherapy (IMRT) as an advanced form of the high precision conformal technique together with inverse treatment planning systems allowed not only higher conformity of irradiation but also a possibility to deliver inhomogeneous doses simultane- 
ously to the volume in a shorter time. IMRT offered an elegant solution compared to 3D-CRT in sparring normal tissue. IMRT allowed closer shaping of dose to target volume using multiple photon beams from different directions with adjusted intensities. Since smaller margin are used, there is a less room for errors on the other hand, especially so-called geographical miss could occur. This more precise technique stresses the importance of proper target volume definition and delineation based on optimal imaging modalities, adequate immobilization of patients, verification of set-up uncertainties and anatomical changes during treatment. IMRT with simultaneous integrated boost (IMRT-SIB) enables to decrease planning uncertainty and facilitates dose escalation in the tumor with better tumor control probability.

IMRT has been established as a primary radiotherapy approach in the treatment of LAHNC with less toxicity [6] and improving of quality of life [6-8] without compromising clinical outcome $[6,9-15]$. The recently published metanalysis [16] of seven randomized controlled trials (RCTs) confirmed that IMRT significantly reduces the risk of moderate to severe acute and late xerostomia compared to two-dimensional radiotherapy (2D-RT) and 3D-CRT in the radical treatment of HNC. However, only one trial [13] demonstrated the superiority in LCR and OS over 3D-CRT and this benefit was limited to nasopharyngeal cancer patients alone.

The aim of our study was to compare the technique of 3D-CRT and IMRT-SIB in the curative treatment of LAHNC and assess the safety and efficacy of slightly dose-escalating IMRT-SIB approach in the treatment outcome and the treatment-related toxicity.

\section{Patients and methods}

Study design and participants. The non-randomized retrospective single-institution study enrolled patients treated with radical radiotherapy for LAHNC and compared two different radiotherapy techniques - 3D-CRT and IMRT-SIB during the time period 1998-2016. Eligible participants had newly diagnosed and histologically confirmed stage III or IV squamous cell carcinoma of nasopharynx, oropharynx, hypopharynx, larynx or oral cavity. Patients with neck carcinoma of the unknown primary origin were also included. Non-squamous histology and patients with salivary gland tumors were excluded. The other exclusion criteria were previous surgery for primary tumor excepting biopsy and nodal neck dissection, and previous radiotherapy for the primary and distant metastasis.

Procedures. Pre-treatment evaluation encompassed complete medical history including smoking and drinking habits, physical examination and laboratory testing. Before the treatment there were dental examination indicated and nutritional status of the patients assessed. The patients in nutritional risk were recommended for feeding tube insertion with percutaneous endoscopic gastrostomy prefer- ably. All the patients underwent the clinical staging at the baseline including panendoscopy with biopsies, CT and/or MRI of head and neck region, and evaluation of the possible distant dissemination (chest $\mathrm{X}$ ray and abdomen ultrasonography). CT of the chest and abdomen. ${ }^{18} \mathrm{~F}$-fluorodeoxyglucose $\left({ }^{18} \mathrm{~F}-\mathrm{FDG}\right)$ PET-CT scan was performed after year 2010. The stage of the disease was scored according to UICC TNM classification, $7^{\text {th }}$ edition [17].

Patients were treated in the supine position on the flat table-top and immobilized in the neutral neck position. The fixation with a thermoplastic mask from skull vertex to shoulder was used. Planning CT scans of head and neck region in 3- or 5-mm intervals were performed and transferred to a three-dimensional treatment planning system. For improving the target volume delineation accuracy fusion with diagnostic images (CT with intravenous iodine contrast, MRI and FDG-PET/CT) were used. Treatment volumes and organs at risk were contoured on each CT image in accordance with ICRU 50, 83 [18-20] and previously published contouring guidelines [21-25]. Gross tumor volume (GTV) encompassed primary tumor volume and involved lymph nodes with respect to physical exam and imaging studies. Clinical target volume included GTV with margin 5-10 mm for microscopic spreading and electively treated lymph nodes. Planning target volume and planning organ at risk volume were created by adding $5 \mathrm{~mm}$ security margin to take into account patient setup uncertainties.

Radiotherapy protocol included two different techniques - 3D-CRT or IMRT-SIB. Two different dose levels were used in this study. 3D-CRT used 3-fields technique consisting of two opposed lateral fields encompassing primary tumor and lymph nodes of both sides of the neck and the third anterior field for irradiating the supraclavicular region. After $40-42$ Gy the lateral photon beams were reduced to protect the spinal cord and additional lateral electron fields were added to treat the posterior neck nodes. The prescribed dose was $70 \mathrm{~Gy}$ in 35 fractions over 7 weeks to the primary tumor and to the involved nodes, and $50 \mathrm{~Gy}$ to the electively treated areas. With the advent of multi-leaf collimator (MLC) 7 field isocentric technique was used.

IMRT-SIB employed 7 field isocentric technique with sliding window leaf sequence. Slightly accelerated fractionation of 33 fractions was used where primary tumor and involved lymph nodes received 69.96 Gy (2.12 Gy per fraction), areas with high risk of subclinical spreading were treated by 61.05 Gy (1.85 Gy per fraction) and electively treated areas received 54.12 Gy (1.64 Gy per fraction). Dose prescription, specification and reporting were performed according to ICRU 50, 62 and 83 recommendations. In the optimization process the following constraints for OAR were used: spinal cord D max $\leq 45 \mathrm{~Gy}$, brain stem $\leq 54 \mathrm{~Gy}$, contralateral parotid gland D mean $\leq 26 \mathrm{~Gy}$.

Radiotherapy should have been completed in the prescribed overall treatment time, proceeding interruption were compensated by 6 times a week irradiation. 
Patients with an Eastern Cooperative Oncology Group (ECOG) performance status of 0 or 1 , normal hematologic and renal function were given concomitant chemotherapy with cisplatin in three weekly $\left(100 \mathrm{mg} / \mathrm{m}^{2}\right)$ or a weekly $(40$ $\mathrm{mg} / \mathrm{m}^{2}$ ) settings. Neoadjuvant chemotherapy based on cisplatin derivatives was indicated less frequently.

Toxicity. Acute toxicity was monitored weekly during the treatment period and then until the complete resolution. After the treatment completion patients were followed every 3 months for 2 years and every 6 months thereafter until death or last follow-up visit. Control imaging was indicated 2-3 months after the treatment completing and clinical and late toxicity evaluation were performed every check-up during the post-treatment period. Acute and late toxicity were reported using Radiation Therapy Oncology Group (RTOG) and European Organisation for Research and Treatment of Cancer (EORTC) scaling system [26, 27].

Outcomes and statistical analysis. The primary endpoint was overall survival (OS). OS was defined as the time between the start of radiotherapy and the last clinical check-up or the date of death of any cause. The secondary endpoints were disease-free survival (DFS), locoregional control (LRC), metastasis-free survival (MFS), and acute and late toxicity. The effect of other factors - type of concomitant therapy, tobacco and alcohol exposure on OS and DFS were also evaluated.

DFS was defined as the time between the start of radiotherapy to the locoregional or distant failure. LRC was defined as the time to locoregional progressive disease of the primary tumor or regional lymph nodes. MFS means the time to distant metastasis detection since start of radiotherapy.

The data were analyzed with statistical software SPSS version 19.0, p-values of less than 0.05 were considered to indicate statistical significance. Univariate analyses of survival were carried out by the Kaplan-Meier method and the evaluation of differences between the groups was performed with the log-rank test. A multivariate analysis of survival using prognostic factors with a p-value less than 0.05 in univariate analyses according to risk factors was performed with the Cox proportional-hazards regression model using forward stepwise method to define the independent contribution of each prognostic factor.

Acute toxicity was defined as toxicity happening during radiotherapy and up 3 months after the end of the treatment. Late toxicity was defined as toxicity which occurred later than 3 months in the post-treatment period. For evaluating differences in toxicity and risk factors between 3D-CRT and IMRT there was used Fischer's exact test. The cut-off date for follow-up analysis was July 31 ${ }^{\text {st }}, 2018$.

\section{Results}

525 patients (93 females, 432 men) enrolled to this study underwent radical treatment of radiotherapy or radiochemotherapy for LAHNC in the Oncology Clinic of Univer- sity Hospital Motol Prague between 01/1998 and 12/2016. 262 patients were treated by 3D-CRT and 263 patients by IMRT-SIB techniques. Patients and tumor characteristics are listed in Table 1. Median follow-up of patients treated 3D-CRT or IMRT-SIB were 62 and 46 months, respectively.

Overall survival. The $1,3,5$-year OS in 3D-CRT group and IMRT-SIB group was $64 \%, 42.2 \%, 33,6 \%$ and $68.7 \%$, $43.3 \%, 29.8 \%$, respectively. No significant difference in OS between the two groups was proven (Figure 1A).

Locoregional control was at 1,3 , and 5 years $68.2 \%$, $62.4 \%$ and $59.5 \%$ in $3 \mathrm{D}-\mathrm{CRT}$ and $66.7 \%, 61.1 \%$ and $59.1 \%$ in IMRT-SIB group. There were no significant differences in LCR in both groups (Figure 1B).

Disease-free survival was at 1,3 , and 5 years $61.2 \%$, $52.4 \%$ and $48.4 \%$ in $3 \mathrm{D}$-CRT group and $59.2 \%, 47.7 \%, 41 \%$ in IMRT-SIB group. These differences were also not significant.

Metastatic-free survival was at 1,3 , and 5 years $91.8 \%$, $84.5 \%$ and $81.2 \%$ in $3 \mathrm{D}-\mathrm{CRT}$ and $82 \%, 71.3 \%$ and $62.9 \%$ in IMRT-SIB group (Figure 1C). There was statistically significant higher incidence of metastasis in the IMRT-SIB group $(\mathrm{p}=0.001 \log$ rank). Because there is no difference in locoregional control and overall survival, we conclude that the explanation is improved follow up technique in the last years (when IMRT was used) in comparison to older 3D-CRT group.

Acute toxicity (mucosal and skin toxicity) was evaluated in 222 patients of 3D-CRT and 258 patients of IMRT-SIB groups (Table 2). Patients treated 3D-CRT developed significantly higher acute toxicity comparing to IMRT-SIB group (mucositis: $\mathrm{p}<0.001$, skin toxicity: $\mathrm{p}<0.001$ ).

Late toxicity: twenty-five patients of $3 \mathrm{D}-\mathrm{CRT}$ and 72 patients of IMRT-SIB completed the late toxicity evaluation questionnaires (Table 3). Salivary gland, mucosal tissue and subcutaneous tissue toxicity, risk of dysphagia and fatigue were evaluated. Most patients developed grade $0-1$ toxicity, with similar results in both groups. The significantly positive results in favor for IMRT ( $\mathrm{p}=0.001)$ were found at xerostomia evaluation. Grade 2 or worse toxicity was found less at IMRT group compared to 3D-CRT group (20 out of 72 [27.7\%] vs. 16 out of 25 [64\%]).

Statistically significant favorable risk factors affecting OS, LCR and DFS in 3D-CRT and IMRT-SIB in the univariate and multivariate analysis were primary sites of nasopharynx, larynx or unknown primary ( $\mathrm{p}<0.001$ log rank), lower clinical stage III ( $p<0.001$ log rank), non-smoking status $(\mathrm{p}<0.001 \log$ rank), abstinence or irregular alcohol consumption $(\mathrm{p}<0.001$ $\log$ rank) and concomitant chemotherapy $(\mathrm{p}<0.001$ log rank) (Table 4, Figure 2).

\section{Discussion}

The OS and LCR are the most important clinical outcomes in the radical treatment of head and neck cancer. Theoretically there may be an increased risk of locoregional failure 
Table 1. Patients, tumor and treatment characteristics. Median (range) is reported for continuous and counts (percentage) for categorical variables. Statistical difference between 3D-CRT and IMRT-SIB group was computed using Chi-square test or Student $t$-test respectively for categorical and continuous variables.

\begin{tabular}{|c|c|c|c|c|}
\hline Variable & Group & 3D-CRT & IMRT-SIB & p-value \\
\hline \multirow[t]{2}{*}{ Age (years) } & & $58.3(14-91)$ & $61.8(33-94)$ & 0.080 \\
\hline & Female & $45(17 \%)$ & $48(18 \%)$ & 0.819 \\
\hline Gender & Male & $217(83 \%)$ & $215(82 \%)$ & \\
\hline \multirow[t]{2}{*}{ Histology grading } & $\mathrm{G} 1 / 2$ & $78(30 \%)$ & $145(55 \%)$ & $<0.001$ \\
\hline & $\mathrm{G} 3 / 4$ & $184(70 \%)$ & $118(45 \%)$ & \\
\hline \multirow[t]{2}{*}{ Clinical stage } & III & $96(37 \%)$ & $64(24 \%)$ & 0.002 \\
\hline & IV & $166(63 \%)$ & $199(76 \%)$ & \\
\hline \multirow[t]{3}{*}{ T stage } & $\mathrm{T} 3$ & $59(25 \%)$ & $55(25 \%)$ & 1.000 \\
\hline & $\mathrm{T} 4$ & $174(75 \%)$ & $165(75 \%)$ & \\
\hline & No & $50(20 \%)$ & $34(15 \%)$ & 0.033 \\
\hline N stage & $\mathrm{N} 1 / \mathrm{N} 2 / \mathrm{N} 3$ & $205(80 \%)$ & $234(85 \%)$ & \\
\hline \multirow[t]{7}{*}{ Primary tumor site } & CUP & $27(10 \%)$ & $42(16 \%)$ & \\
\hline & Hypopharynx & $26(10 \%)$ & $45(17 \%)$ & $<0.001$ \\
\hline & Larynx & $40(15 \%)$ & $38(14 \%)$ & \\
\hline & Nasopharynx & $46(18 \%)$ & $14(5 \%)$ & $<0.001$ \\
\hline & Oral cavity & $25(10 \%)$ & $28(11 \%)$ & \\
\hline & Oropharynx & $98(37 \%)$ & $96(37 \%)$ & \\
\hline & Yes & $99(38 \%)$ & $29(11 \%)$ & $<0.001$ \\
\hline \multirow[t]{2}{*}{ Neoadjuvant chemotherapy } & No & $163(62 \%)$ & $234(89 \%)$ & \\
\hline & Cisplatin & $91(35 \%)$ & $172(66 \%)$ & $<0.001$ \\
\hline \multirow[t]{3}{*}{ Concurrent chemo/bio/radiotherapy } & Cetuximab & $2(1 \%)$ & $17(6 \%)$ & \\
\hline & RT alone & $169(64 \%)$ & $74(28 \%)$ & \\
\hline & Weekly & $34(37 \%)$ & $74(43 \%)$ & 0.430 \\
\hline \multirow[t]{2}{*}{ Concurrent cisplatin regimen } & 3weekly & $57(63 \%)$ & $98((57 \%)$ & \\
\hline & Yes & & & \\
\hline \multirow{2}{*}{ Smoking history } & No & $135(72 \%)$ & $193(74 \%)$ & 0.667 \\
\hline & & $53(28 \%)$ & $68(26 \%)$ & \\
\hline \multirow[t]{2}{*}{ Alcohol abuse history } & Yes & $94(50 \%)$ & $147(57 \%)$ & 0.211 \\
\hline & No & $93(50 \%)$ & $113(43 \%)$ & \\
\hline \multirow[t]{2}{*}{ Immunohistochemistry p16 } & Positive & 0 & 15 & 1.000 \\
\hline & Negative & 0 & 8 & \\
\hline
\end{tabular}

T stage Primary Tumor according to UICC $7^{\text {th }}$ edition; N stage Regional Lymph Nodes according to UICC $7^{\text {th }}$ edition; G grade, CUP (cancer of unknown origin), 3D-CRT (3D-conformal radiotherapy), IMRT-SIB (intensity modulated radiotherapy with simultaneous integrated boost)
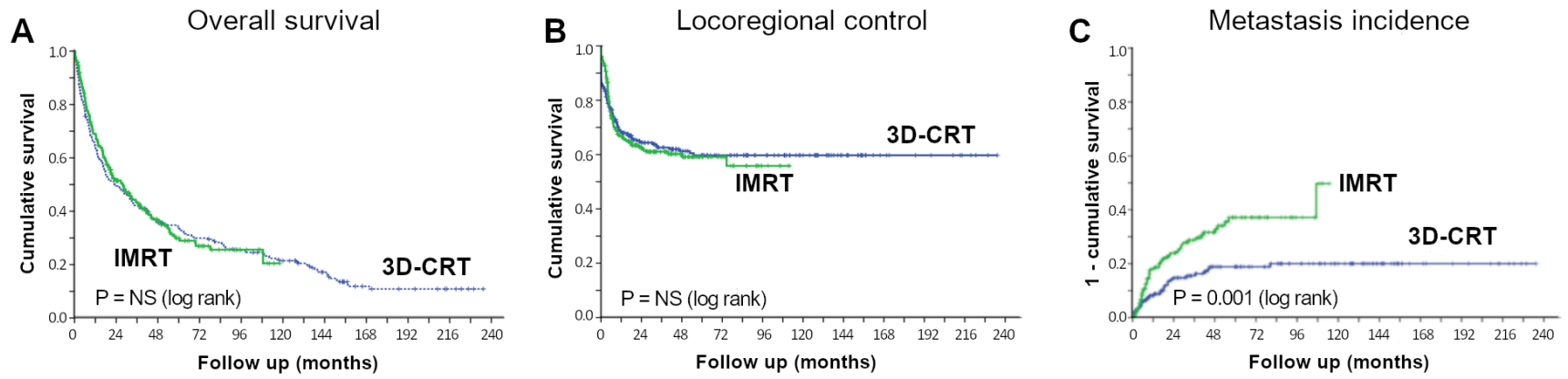

Figure 1. Kaplan-Meier plots of overall survival (A), locoregional control (B) and metastasis incidence (C). 
Table 2. Acute toxicities were reported using RTOG and EORTC scaling system.

\begin{tabular}{lcccc}
\hline Toxicity & Grade & $\begin{array}{c}\text { 3D-CRT } \\
(\mathbf{n = 2 2 2})\end{array}$ & $\begin{array}{c}\text { IMRT-SIB } \\
(\mathbf{n = 2 5 8})\end{array}$ & p-value \\
\hline Mucositis & G0-1 & 6 & 33 & \\
& G2-4 & 216 & 225 & $<0.001$ \\
Skin toxicity & G0-1 & 11 & 30 & \\
& G2-4 & 211 & 228 & $<0.001$ \\
\hline
\end{tabular}

Table 3. Late toxicity - Late toxicity were reported using Radiation Therapy Oncology Group (RTOG) and European Organisation for Research and Treatment of Cancer (EORTC) scaling system.

\begin{tabular}{lcccc}
\hline Toxicity & Grade & $\begin{array}{c}\text { 3D-CRT } \\
(\mathbf{n = 2 5})\end{array}$ & $\begin{array}{c}\text { IMRT-SIB } \\
(\mathbf{n = 7 2})\end{array}$ & p-value \\
\hline $\begin{array}{l}\text { Fatigue } \\
\text { (grade) }\end{array}$ & $\mathrm{G} 0-1$ & 20 & 63 & 0.344 \\
$\begin{array}{l}\text { Subcutaneous tissue } \\
\text { (fibrosis) }\end{array}$ & $\mathrm{G} 2-4$ & 5 & 9 & \\
Salivary glands & $\mathrm{G} 2-4$ & 20 & 62 & 0.525 \\
(xerostomia) & $\mathrm{G} 0-1$ & 9 & 10 & \\
Esophagus & $\mathrm{G} 2-4$ & 16 & 20 & $\mathbf{0 . 0 0 2}$ \\
(dysphagia) & $\mathrm{G} 0-1$ & 15 & 61 & $\mathbf{0 . 0 2 1}$ \\
Dysgeusia & $\mathrm{G} 2-4$ & 10 & 11 & \\
& $\mathrm{G} 0-1$ & 20 & 64 & 0.310 \\
\hline
\end{tabular}

with more precise technique as the IMRT because there is a less room for errors. Several RCTs [6, 9-15] evaluated disease-related endpoints between IMRT with 2D-CRT/3DCRT. Only a single trial each used OS [13] and LCR [34] as a primary endpoint identically to our study.

Nutting et al. [6] in 2011 evaluated 94 patients with oropharyngeal cancer who were randomized to receive either 2D-CRT or IMRT. No differences in LCR or OS were proven in 24-month follow-up between both groups. Gupta et al. [11] involved 60 patients with oropharyngeal cancer in their trial, where 28 patients were treated with 3D-CRT and 32 with IMRT. The results of this study were published in 2012. A median follow-up was 40 months and 3-year LCR for 3D-CRT and IMRT groups were $88.2 \%$ and $80.5 \%$, respectively $(\mathrm{p}=0.45)$ and 3 -year OS $70.6 \%$ and $68 \%(\mathrm{p}=0.81)$. No statistically significant differences were proven.

Ghosh-Laskar et al. [12] published results of their trial in 2016. Fifty-nine evaluated patients with HNC were treated either 3D-CRT or IMRT with median follow-up 70 months. No differences in LCR or OS benefit were seen in both groups. 5 -year OS rates for 3D-CRT and IMRT were $50.7 \%$ and 64.3 , respectively $(\mathrm{p}=1.1)$. The 5 -year LRC rates for $3 \mathrm{D}$-CRT and IMRT were $62.9 \%$ and $69.2 \%$, respectively $(\mathrm{p}=0.2)$. Bourhis et al. [15] in their trial compared 94 patients in each arm treated 3D-CRT or IMRT with concomitant chemotherapy for LAHNC stage III-IV. The primary endpoint of their study was LCR. Patient were randomized between IMRT with higher dose (75 Gy/7weeks) and 3D-CRT with standard
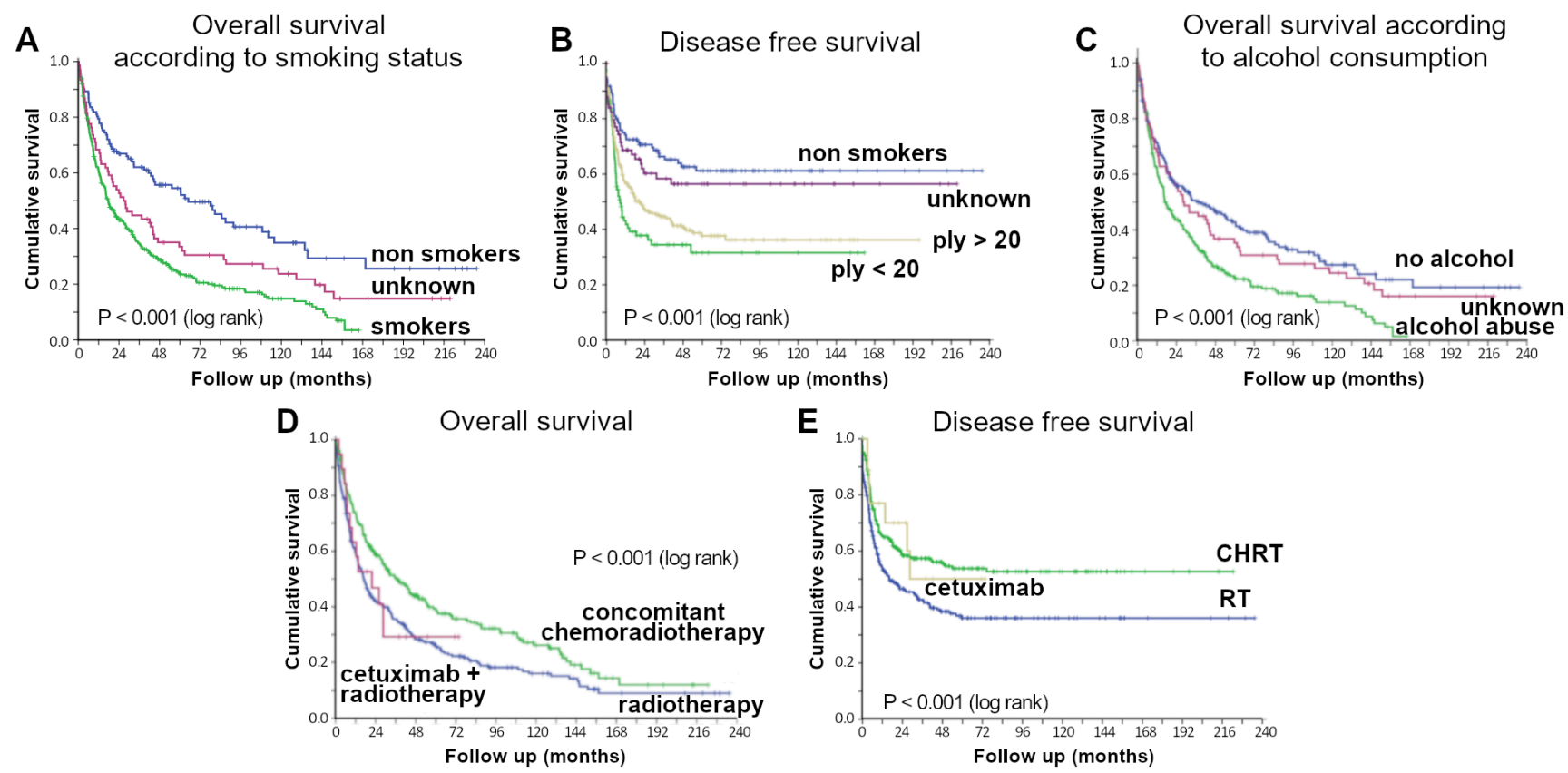

Figure 2. Kaplan-Meier plots of overall survival and locoregional control according to risk factors. 
Table 4. Univariate analysis - Kaplan-Meier analysis of differences between the groups with the log-rank test. A multivariate analysis of survival according to risk factors was performed with the use of the Cox proportional-hazards regression model using forward stepwise method.

\begin{tabular}{|c|c|c|c|c|c|c|}
\hline & $\begin{array}{c}\text { OS-univariate- } \\
\text { analysis }\end{array}$ & $\begin{array}{l}\text { OS-multivariate- } \\
\text { analysis }\end{array}$ & $\begin{array}{c}\text { LCR-univariate- } \\
\text { analysis }\end{array}$ & $\begin{array}{l}\text { LCR-multivariate- } \\
\text { analysis }\end{array}$ & $\begin{array}{c}\text { DFS-univariate- } \\
\text { analysis }\end{array}$ & $\begin{array}{c}\text { DFS-multivariate- } \\
\text { analysis }\end{array}$ \\
\hline Gender (F vs $M)$ & NS & ND & NS & ND & NS & ND \\
\hline Stage (III vs IV) & $<0.001$ & $<0.001$ & $<0.001$ & 0.027 & $<0.001$ & $<0.001$ \\
\hline Primary site & $<0.001$ & $<0.001$ & $<0.001$ & $<0.001$ & $<0.001$ & $<0.001$ \\
\hline Grading ( $1 / 2$ vs $3 / 4)$ & NS & ND & NS & ND & NS & ND \\
\hline $\begin{array}{l}\text { Smoking status(smokers vs. } \\
\text { non-smokers) }\end{array}$ & $<0.001$ & $<0.001$ & $<0.001$ & $<0.001$ & $<0.001$ & $<0.001$ \\
\hline $\begin{array}{l}\text { Smoking status }(\mathrm{p} / \mathrm{y}>20<\mathrm{vs} \\
\text { non-smokers) }\end{array}$ & $<0.001$ & $<0.001$ & $<0.001$ & 0.002 & $<0.001$ & $<0.001$ \\
\hline Alcohol cons. & $<0.001$ & NS & 0.019 & NS & $<0.002$ & NS \\
\hline Concomitant CHT & 0.002 & $<0.001$ & 0.009 & 0.003 & 0.001 & $<0.001$ \\
\hline $\begin{array}{l}\text { Concomitant CHT(cisplatin } \\
3 \mathrm{w} \text { vs w) }\end{array}$ & NS & $\mathrm{ND}$ & NS & $\mathrm{ND}$ & NS & ND \\
\hline NAC & NS & ND & NS & ND & NS & ND \\
\hline Immunohistochemistry p16 & 0.006 & NS $(0.051)$ & NS & ND & 0.008 & 0.021 \\
\hline
\end{tabular}

Gender-F-females, M-men; Smoking -p/y-package years; CHT-chemotherapy; 3w vs w - three weekly versus weekly; NAC - neoadjuvant chemotherapy; NS - not significant; ND - not done;

dose (70 Gy/7weeks). With the median follow-up 4.7 years, neither LCR nor OS were significantly different in the both arms. Unfortunately, this study was terminated prematurely due to slow accrual and adoption IMRT technique as a standard treatment strategy in France.

The significantly positive results in favor for IMRT were found in trial of Peng et al. [13] where only patients with nasopharyngeal cancer were included. Six hundred sixteen patients were randomized to be treated by $2 \mathrm{D}$-RT or IMRT. 5 -year LC was $81.5 \%$ in IMRT arm and $62.2 \%$ in 2D-RT arm $(\mathrm{p}=0.05)$ in the case of T4 tumor. Five-year OS in IMRT and 2D-RT was $79.6 \%$ and $67.1 \%$, respectively $(\mathrm{p}=0.02)$.

The disease-related endpoints of our non-randomized study corresponds with above-mentioned RCTs. No statistically significant differences in LCR and OS were found between the 3D-CRT and IMRT-SIB groups despite the higher dose delivered to the GTV in patients treated with IMRT-SIB. On the other hand, there was statistically significant higher incidence of distant metastasis in the IMRT-SIB group ( $\mathrm{p}=0.001 \log$ rank). Because no difference in LCR and OS was proven between the two groups, a likely explanation are changes in follow-up during IMRT era. More precise imaging methods such a PET scan have been put into followup algorithm recently. Another explanation could be that in IMRT-SIB group higher proportion of stage IV patient were enrolled.

The HNC treatment intensification with the addition of chemotherapy or radiotherapy escalation leads to increased toxicity at the same time. IMRT allows to improve the therapeutic ratio resulting in better toxicity profile.

Several RCTs compared acute and late toxicity between 2D-RT/3D-CRT and IMRT. Mucositis, dermatitis, odynophagia, dysphagia and dysgeusia are the most common acute toxicity during HNC RT. They can affect an adequate oral intake resulting in weight loss and sometimes can lead to treatment interruption with potential impact to clinical outcome. Mucositis is a very common adverse event during RT and the incidence is influenced more by primary site of the tumor and concomitant chemotherapy than radiotherapy technique. In RCT of Gupta et al. [11] no difference was found in acute mucositis severity between 3D-CRT and IMRT in group of 60 patients. When looking at mucositis grade 2 or worse a difference can be seen. 26 of 28 patients in $3 \mathrm{D}$-CRT compared to 25 of 32 patients in IMRT groups resulted this level of toxicity.

In our study, 216 of 222 patients in 3D-CRT arm and 225 of 258 patients in IMRT-SIB arm developed mucositis grade 2 or worse, which was a statistically significant difference in favor of IMRT-SIB. However, our retrospective non-randomized study could be prone to bias and the results should be interpreted with care.

The level of acute skin toxicity during HNC radiotherapy corresponds with severity of late skin and subcutaneous tissue toxicity according to the study of Nevens et al. [29]. Radiodermatitis grade 3 or worse at the end of RT develops fibrosis 2 or worse in 6 months after RT based on RTOG criteria. It was supposed that IMRT can cause severe acute dermatitis in compare to 3D-CRT. The above-mentioned studies [6, $11,12]$ did not confirm this prediction. Not only there were no differences in acute radiodermatitis between 3D-CRT and IMRT, but late subcutaneous fibrosis was less frequent in IMRT treated patients [13]. Two hundred eleven of 222 patients in 3D-CRT and 228 of 258 patients in IMRT-SIB groups in our study had grade 2 or worse acute dermatitis and statistically significant difference in favor of IMRT-SIB group was found. These results were not confirmed in late 
subcutaneous fibrosis where no difference between the two groups were proven.

RT of HNC can cause a different kind of late toxicity xerostomia, dysphagia, skin fibrosis or fatigue. The most debilitating adverse event is xerostomia caused by salivary glands hypofunction resulting in permanent oral discomfort with swallowing and speech difficulties. Several randomized trials $[6,9-14,28]$ compared salivary glands toxicity between patients treated by $2 \mathrm{D}-\mathrm{RT}$ or $3 \mathrm{D}-\mathrm{CRT}$, and IMRT. All of them concluded that IMRT reduces the delivering dose to the contralateral parotid gland and decreases xerostomia compared to conventional technique.

Nutting et al. [6] in their phase 3 multicenter randomized controlled trial "Parotid-sparing intensity modulated versus conventional radiotherapy in head and neck cancer (PARSPORT)" evaluated salivary toxicity using questionnaires and salivary flow before and after radiotherapy. The absolute difference of xerostomia grade 2 or worse in 24 months after radiotherapy were $54 \%$ in favor for IMRT ( $83 \%$ in the $3 \mathrm{D}$-CRT group vs. $29 \%$ in the IMRT group). These results were independent to the primary tumor site, disease stage or usage of neoadjuvant chemotherapy. Salivary toxicity grade 2 or worse was a primary endpoint in study of Gupta et al. [11]. The evaluation of xerostomia was based on the RTOG criteria and physician rate. Significantly lower proportion of xerostomia grade 2 or worse was found after IMRT treatment compared with 3D-CRT ( $59 \%$ vs. $89 \%, \mathrm{p}=0.009$ ).

Swallowing problems are common long-term treatmentrelated toxicity identified as a very distressing symptom according to the patient experience. Dysphagia can occur in up to $50 \%$ of patients after chemoradiotherapy for HNC [30]. Pharyngeal constrictors and supraglottic larynx are the most important anatomical structures responsible for the proper swallowing function [31-33]. The major clinical consequences of dysphagia are dietary modifications, nutritional deficiencies and the risk of aspiration [31]. To confirm the reduction of swallowing toxicity by special IMRT technique - dysphagia optimized intensity modulated radiotherapy - a new randomized trial was setup in 2016 [34].

Fatigue has a multifactorial etiology which can be caused by combination of radiotherapy, chemotherapy, nutritional factors and stress. Nutting et al. [6] surprisingly found that the patients treated by IMRT technique suffered more from fatigue in compare to the patients with conventional treatment (74\% vs. $41 \%, \mathrm{p}=0.0015$ ). They suggested the higher dose to the posterior fossa by IMRT technique as a possible explanation of the higher fatigue incidence. Late side-effects of the treatment were evaluated in our study. Twenty-five patients of 3D-CRT arm and 72 patients of IMRT-SIB arm completed the EORTC/RTOG late toxicity evaluation questionnaires during their last follow-up visit. Salivary gland, mucosal tissue and subcutaneous tissue toxicity, risk of dysphagia and fatigue were evaluated. Most patients developed grade 0-1 toxicity, with similar results in both groups. The significantly positive results in favor for IMRT-SIB group $(p=0.001)$ were found at xerostomia evaluation. Grade 2 or worse toxicity was found less at IMRT group compared to 3D-CRT group (20 out of $72[27.7 \%]$ vs. 16 out of 25 [64\%]). A weakness of these results could be that only a part of patients of both groups were evaluated in the different time-points.

In our study, we found several statistically significant risk factors, which positively affected OS, LCR and DFS as primary sites of nasopharynx, larynx or unknown primary, lower clinical stage III, non-smoking status, abstinence or irregular alcohol consumption and concomitant chemotherapy. These favorable risk factors were similar in 3D-CRT and IMRT-SIB arms.

In our study, we confirmed that IMRT-SIB is a safe radiotherapy method where less toxicity can be reached without compromising local control and overall survival in comparison with the older $3 \mathrm{D}$ conformal technique. No statistically significant differences in LCR and OS were found in our study between the 3D-CRT and IMRT-SIB groups, despite the higher dose delivered to the GTV in patients treated with IMRT-SIB. Significantly lower MFS without compromising OS and LCR in IMRT-SIB group could be explained by more precise follow-up of IMRT-SIB group and implementation of functional imagine methods (PET/CT) to the diagnostic algorithm. Acute toxicity (mucosal and skin toxicity) was significantly reduced in patients treated by IMRT-SIB. From late toxicity evaluations the most important was significantly reduced xerostomia in IMRT-SIB treated patients.

\section{References}

[1] FITZMAURICE C, ALLEN C, BARBER RM, BARREGARD L, BHUTTA ZA et al. Global, regional, and national cancer incidence,mortality, years of life lost, years lived with disability, and disability-adjusted life-years for 32 cancer groups, 1990 to 2015. JAMA Oncol 2017; 3: 524-548. https://doi. org/10.1001/jamaoncol.2016.5688

[2] DUSEK L, MUZIK J, KUBASEK M, KOPTIKOVA J, ZALOUDIK J et al. Epidemiology of Malignant Tumors in the Czech Republic [online]. Masaryk University, Czech Republic, 2005. http://www.svod.cz, version 7.0. Accessed 2018-6-14.

[3] PYTYNIA KB, DAHLSTROM KR, STIRGIS EM. Epidemiology of HPV-associated oropharyngeal cancer. Oral Oncol 2014; 50: 380-386. https://doi.org/10.1016/j.oraloncology.2013.12.019

[4] BOURHIS J, OVERGAARD J, AUDRY H, ANG KK, SAUNDERS $M$ et al. Hyperfractionated or accelerated radiotherapy in head and neck cancer: a meta-analysis. Lancet 2006; 368: 843-854. https://doi.org/10.1016/S0140-6736(06)69121-6

[5] PIGNON JP, LE MAITRE A, MAILLARD E, BOURHIS J. Meta-analysis of chemotherapy in head and neck cancer (MACH-NC): An update on 93 randomised trials and 17,346 patients. Radiother Oncol 2009; 92: 4-14. https://doi. org/10.1016/j.radonc.2009.04.014 
[6] NUTTING CM, MORDEN JP, HARRINGTON KJ, URBANO TG, BHIDE SA et al. Parotid-sparing intensity modulated versus conventional radiotherapy in head and neck cancer (PARSPORT): A phase 3 multicentre randomised controlled trial. Lancet Oncol 2011; 12: 127-136. https://doi. org/10.1016/S1470-2045(10)70290-4

[7] RATHOD S, GUPTA T, GHOSH-LASKAR S, MURTHY V, BUDRUKKAR A et al. Quality-of-life (QOL) outcomes in patients with head and neck squamous cell carcinoma (HNSCC) treated with intensity-modulated radiation therapy (IMRT) compared to three-dimensional conformal radiotherapy (3D-CRT): Evidence from a prospective randomized study. Oral Oncol 2013; 49: 634-642. https://doi. org/10.1016/j.oraloncology.2013.02.013

[8] World Health Organization. Division of Mental Health and Prevention of Substance Abuse. WHOQOL: measuring quality of life. Geneva, World Health Organization. 1997; http://www.who.int/iris/handle/10665/63482

[9] POW EH, KWONG DL, MCMILLAN AS, WONG MC, SHAM JS et al. Xerostomia and quality of life after intensity-modulated radiotherapy vs. conventional radiotherapy for early stage nasopharyngeal carcinoma: initial report on a randomized controlled clinical trial. Int J Radiat Oncol Biol Phys 2006; 66: 981-991. https://doi.org/10.1016/j. ijrobp.2006.06.013

[10] KAM MK, LEUNG SF, ZEE B, CHAU RM, SUEN JJ et al. Prospective randomized study of intensity modulated radiotherapy on salivary gland function in early-stage nasopharyngeal carcinoma patients. J Clin Oncol 2007; 25: 48734879. https://doi.org/10.1200/JCO.2007.11.5501

[11] GUPTA T, AGARWAL J, JAIN S, PHURAILATPAM R, KANNAN et al. Three-dimensional conformal radiotherapy (3D-CRT) versus intensity modulated radiation therapy (IMRT) in squamous cell carcinoma of the head and neck: a randomized controlled trial. Radiother Oncol 2012; 104: 343-348. https://doi.org/10.1016/j.radonc.2012.07.001

[12] GHOSH-LASKAR S, YATHIRAJ PH, DUTTA D, RANGARAJAN V, PURANDARE $\mathrm{N}$ et al. Prospective randomized controlled trial to compare 3-dimensional conformal radiotherapy to intensity-modulated radiotherapy in head and neck squamous cell carcinoma: Long-term results. Head Neck 2016; 38: 1481-1487. https://doi.org/10.1002/ hed. 24263

[13] PENG G, WANG T, YANG KY, ZHANG S, ZHANG T et al. A prospective, randomized conventional two-dimensional radiotherapy for the treatment of nasopharyngeal carcinoma. Radiother Oncol 2012; 104: 286-293. https://doi. org/10.1016/j.radonc.2012.08.013

[14] SPIOTTO MT, WEICHSELBAUM RR. Comparison of 3D confromal radiotherapy and intensity modulated radiotherapy with or without simultaneous integrated boost during concurrent chemoradiation for locally advanced head and neck cancers. PLoS One 2014; 9: e94456. https://doi. org/10.1371/journal.pone.0094456

[15] BOURHIS J, AUPERIN A, ALFONSI M, SUN XU S, RIVES $\mathrm{M}$ et al. Dose escalation of radiotherapy (RT) for locally advanced head and neck carcinomas treated with concomitant chemotherapy (CT) and RT: results of the GORTEC 2004 \pm 01 randomized trial. J Clin Oncol 2017; 35: 6015. https://doi. org/10.1200/JCO.2017.35.15_suppl.6015
[16] GUPTA T, KANNAN S, GHOSH-LASKAR S, AGARWAL JP. Systematic review and meta-analyses of intensity-modulated radiation therapy versus conventional two-dimensional and/or or three-dimensional radiotherapy in curative-intent management of head and neck squamous cell carcinoma. PLoS One 2018 ;13: e0200137. https://doi.org/10.1371/journal.pone. 0200137

[17] SOBIN LH, GOSPODAROWICZ MK, WITTEKIND C. (Eds.). TNM classification of malignant tumors, 7th Edition. Wiley-Blackwell, Chichester 2009, p 336. ISBN 978-1-44433241-4.

[18] LANDBERG T, CHAVAUDRA J, DOBBS J, HANKS G, JOHANSSON KA et al. ICRU REPORT 50. Prescribing, recording and reporting photon beam therapy. J ICRU 1993; os26: 1. https://doi.org/10.1093/jicru/os26.1.Report5

[19] LANDBERG T, CHAVAUDRA J, DOBBS J, GERARD JP, HANKS G et al. Prescribing, recording and reporting photon beam therapy (supplement to ICRU report 50). J ICRU 1999; os32: 1. https://doi.org/10.1093/jicru/os32.1.Report62

[20] ICRU REPORT 83. Prescribing, recording, and reporting photon-beam intensity-modulated radiation therapy (IMRT). J ICRU 2010; 10: 1. https://doi.org/10.1093/ jicru/10.1.Report83

[21] GREGOIRE V, LEVENDAG P, ANG KK, BERNIER J, BRAAKSMA $M$ et al. CT-based delineation of lymph node levels and related CTVs in the node-negative neck: DAHANCA, EORTC, GORTEC, NCIC, RTOG consensus guidelines. Radiother Oncol 2003; 69: 227-236. https://doi. org/10.1016/j.radonc.2003.09.011

[22] GRÉGOIRE V, EISBRUCH A, HAMOIR M, LEVENDAG P. Proposal for the delineation of the nodal CTV in the nodepositive and the post-operative neck. Radiother Oncol 2006; 79: 15-20. https://doi.org/10.1016/j.radonc.2006.03.009

[23] GRÉGOIRE V, COCHE E, COSNARD G, HAMOIR M, REYCHLER H. Selection and delineation of lymph node target volumes in head and neck conformal radiotherapy. Proposal for standardizing terminology and procedure based on the surgical experience. Radiother Oncol 2000; 56: 135-150. https://doi.org/10.1016/S0167-8140(00)00202-4

[24] GREGOIRE V, ANG K, BUDACH W, GRAU C, HAMOIR M et al. Delineation of the neck node levels for head and neck tumors: a 2013 update. DAHANCA, EORTC, HKNPCSG, NCIC CTG, NCRI, RTOG, TROG consensus guidelines. Radiother Oncol 2014; 110: 172-181. https://doi.org/10.1016/j. radonc.2013.10.010

[25] BROUWER CHL, STEENBAKKERS RJHM, BOURHIS J, BUDACH W, GRAU C et al. CT-based delineation of organs at risk in the head and neck region: DAHANCA, EORTC, GORTEC, HKNPCSG, NCIC CTG, NCRI, NRG Oncology and TROG consensus guidelines. Radiother Oncol 2015; 117: 83-90. https://doi.org/10.1016/j.radonc.2015.07.041

[26] DENIS F, GARAUD P, BARDET E, ALFONSI M, SIRE C et al. Late toxicity results of the GORTEC 94-01 randomized trial comparing radiotherapy with concomitant radiochemotherapy for advanced-stage oropharynx carcinoma: comparison of LENT/SOMA, RTOG/EORTC, and NCICTC scoring systems. Int J Radiat Oncol Biol Phys 2003; 55: 93-98. https://doi.org/10.1016/S0360-3016(02)03819-1 
[27] COX DJ, STETZ J, PAJAK TF. Toxicity criteria of the Radiation Therapy Oncology Group (RTOG) and the European Organisation for Research and Treatment of Cancer (EORTC). Int J Radiat Oncol Biol Phys 1995; 31: 1341-1346. https://doi.org/10.1016/0360-3016(95)00060-C

[28] BRAAM PM, TERHAARD CHJ, ROESINK JM, RAAIJMAKERS CP. Intensity-modulated radiotherapy significantly reduces xerostomia compared with conventional radiotherapy. Int J Radiat Oncol Biol Phys 2006; 66: 975-980. https://doi.org/10.1016/j.ijrobp.2006.06.045

[29] NEVENS D, DUPREZ F, DAISNE JF, LAENEN A, DE NEVE $\mathrm{W}$ et al. Radiotherapy induced dermatitis is a strong predictor for late fibrosis in head and neck cancer. The development of a predictive model for late fibrosis. Radiother Oncol 2017; 122: 212-216. https://doi.org/10.1016/j.radonc.2016.08.013

[30] ROE JWG, DRINNAN MJ, CARDING PN, HARRINGTON KJ, NUTTING CM. Patient-reported outcomes following parotid-sparing intensity-modulated radiotherapy for head and neck cancer. How important is dysphagia? Oral Oncol 2014; 50: 1182-1187. https://doi.org/10.1016/j.oraloncology.2014.09.009
[31] XU B, BOERO IJ, HWANG L, LE QT, MOISEENKO V et al. Aspiration pneumonia after concurrent chemoradiotherapy for head and neck cancer. Cancer 2015; 121: 1303-1311. https://doi.org/10.1002/cncr.29207

[32] EISBRUCH A, SCHWARTZ M, RASCH C, VINEBERG $\mathrm{K}, \mathrm{DAMEN} \mathrm{E}$ et al. Dysphagia and aspiration after chemoradiotherapy for head-and-neck cancer: which anatomic structures are affected and can they be spared by IMRT? Int J Radiat Oncol Biol Phys 2004; 60: 1425-1439. https://doi. org/10.1016/j.ijrobp.2004.05.050

[33] DUPREZ F, MADANI I, DE POTTER B, BOTERBERG T, DE NEVE W. Systematic review of dose-volume correlates for structures related to late swallowing disturbances after radiotherapy for head and neck cancer. Dysphagia 2013; 28: 337-349. https://doi.org/10.1007/s00455-013-9452-2

[34] PETKAR I, ROONEY K, ROE JWG, PATTERSON JM, BERNSTEIN D et al. DARS: a phase III randomised multicentre study of dysphagia-optimised intensity-modulated radiotherapy (Do-IMRT) versus standard intensity-modulated radiotherapy (S-IMRT) in head and neck cancer. BMC Cancer 2016; 16: 770-780. https://doi.org/10.1186/s12885-0162813-0 